\title{
A Sociolinguistic Study of Social Stratification in Jharkhand and Its Impact on Academic Performance in English at Secondary Level Education
}

\author{
${ }^{1}$ Anita Kumari ${ }^{2}$ Arvind Kumar \\ ${ }^{I}$ Research Scholar, Department Of English, VinobaBhave University, Hazaribagh, Jharkhand - \\ 825301,Jharkhand (India) \\ ${ }^{2}$ Department Of Humanities ., B.I.T Sindri, Dhanbad,Jharkhand
}

\begin{abstract}
The presence of social stratification in every society is an open secret issue. It has multidimensional effects on people's food habit, life style, expectation, and education etc. The purpose of this study is to find out a relationship between social stratification in Jharkhand(India) and its impact on students' academic performance in English at secondary level education. In doing so an empirical study has been conducted. Data were collected from secondary level students and English teachers through questionnaire. The analysis of the data of this study seeks to show that students' academic performance in English co-relates with their social status, economic condition, family background and area of residence etc. As such varied performance of different groups of students is related to social stratification; hence finding out any single solution to this deep rooted issue is virtually impossible. However, to reduce the gaps among different groups of students some recommendations of experienced English teachers have been suggested in this paper.
\end{abstract}

Keywords: social stratification, multidimensional, academic performance.

\section{INTRODUCTION}

Research has established the place of social interaction, social activity and social context in language acquisition (Vygotsky, 1978). Language is one of the potent weapons of any progressive society. The society is made or marred by the roles played by the communicative skills and imperatives of the available languages in a society. The descriptive study of the effect of any and all aspects of society, including cultural norms, expectations, and context,on the way language is used is called sociolinguistics. It is the overall effect of the society on language use. It also studies how language varieties differ between groups separated by certain social variables, for instance ethnicity, religion, status, gender, level of education, age, etc., and how creation and adherence to these rules are used to categorize individuals in social or socioeconomic classes. As the usage of a language varies from place to place, language usage also varies among social classes.

Jharkhand, one of the states of the Union of India which came to existence in November 2000.

In Jharkhand, education starts at the age of 5, when the children are admitted to schools. The schools, which form the basis of education at Jharkhand, are affiliated to either the State Board or CBSE or ICSE. It is noteworthy that the government schools in Jharkhand are vernacular medium schools, where Hindi is the medium of instruction. Besides, the government schools, Education department of Jharkhand also consists of English medium schools.

In majority of the schools under JSEB, English is taught from class III. Like other states in India,the teaching is carried out through the Grammar Translation Method (GTM) that puts stress ongrammar and vocabulary. Generally, in these schools, the teaching process follows a system where the vernacular meanings of English words and phrases are given to the students and they learn it by rote. But, mostly it is seen that teachers themselves are not well-equipped to teach correct English pronunciation, speaking or reading skills to students (Tickoo, 2004). The reason being these teachers are the same people who have passed out from a similar educational system, where their exposure to English had been at the most basic level. Even trained graduate teachers who pass out from the Universities of Jharkhand are not exposed to phonetics or Standard Englishpronunciation as no university in the state teaches phonetics or spoken English during thegraduate years. As most of the teachers themselves had limited exposure in mastering languageskills, they complete their degree program with average language proficiency and in turn followsimilar strategies in teaching their students. Specialized English teachers are quite few in number and hence a vicious circle is created in the teachinglearning process. 
This scenario is not specific to Jharkhand but is seen in most other states of India. (Gokak (1964) points out that "The foundational years for the teaching of English in schools are in the hands of teachers who neither know enough English nor are familiar with the latest and far- reaching developments in the pedagogy of English" .English is the medium of instruction in the schools affiliated to the Central Board of SecondaryEducation (CBSE), New Delhi, and to the Indian Council of Secondary Education (ICSE), NewDelhi. These are the two central level boards that have schools affiliated to them throughout thecountry. But, interaction with the students, parents and teachers from some of these schools inJharkhand, reveals that students get exposed to English language only for a few hours during theEnglish classes, and for the rest of the classes, no real importance is placed on speaking andwriting grammatically correct sentences. The students pass the secondary examination withEnglish as a second language without getting real exposure to sound English teaching practicesAs a result, even if they are able to cope with the English medium education at the HigherSecondary and under graduate level, their speaking and writing skills in English continue toremain inadequate. As pointed out by Tickoo (2004), the whole teaching-learning system couldbe stated to be at fault for this lack of English proficiency in our students, as they are taught byteachers who may not always be highly proficient in its use. The minimum qualificationprescribed for English teachers by CBSE and ICSE and the Higher Secondary Boards ofdifferent states is a Post Graduate degree in the subject concerned, in addition to a Bachelor ofEducation (B.Ed.) degree. However, in many public schools in Jharkhand, Postgraduates withoutB.Ed. are teaching English in Higher Secondary classes, resulting in certain negative teachingoutcomes, particularly in the language teaching process.

Jharkhand is a developing State . During the past one decadeJharkhandi students have done relatively well in various aspects of education as well as in academic performance. Conversely, a notable but unfortunate feature of educational development in the state is the inequality that exists between different groups in the population (Analysis by News paper 2009-10,2010-2011, 2011-2012,2012-2013). In education, overall progress is in upward trend but it has not developed in a balanced way. A hapless feature of education development in the State, however, is the inequality. Inequality exists in terms of school type, stream of education, geographical location and socioeconomic status.

In this study, the researcher has not taken any standard test to measure the better or lower performance in English of secondary level students, their academic GPA in English of Secondary School Certificate Examinations (SSC) is considered as the criteria of performance in English. If a student has obtained lower score in English in comparison with his over-all CGPA then his performance in English is considered poor/low. On the contrary, if a student's English GPA is found equal to or higher than his overall CGPA then his performance is counted as better performance/success.

In this study the ground of our assumption was that- "Socially, economically and psychologically advantaged students perform better in their academic examination especially in English". And our focus was on social stratification and its impact on academic performance in English rather than finding out the reasons of individual variation in English performance at secondary level education in Jharkhand. This dissertation investigates 110 secondary level students and 45 secondary and higher secondary level English teachers' selfreported information, perception and belief about social stratification and its impact on academic result in English

\section{RESEARCH QUESTIONS}

At secondary level examination, the success (passing) rate of students is increasing day by day. But it is the common scenario in Jharkhand that the students coming from rural area, poor economic and uneducated family background cannot demonstrate better performance in academic examinations; especially in English their better performance rate is very low. After the publication of SSC result a comparative analysis of urban versus rural educational institutions is done in various newspapers( Prabhatkhabar ,Hindustan -2013) .In such analysis different explanations are given for poor performance in English of rural, poor, and disadvantaged students. But the explanations for such differences are not consistent as well. So it is important to know the reasons of such unequal performance of different groups of students coming from different social class, area, family background etc[13]. In this study the researcher has set the following hypothesizes or research questions:

a. Is there any difference in the academic performance in English in terms of urban versus rural students, economically rich versus poor students, and students from educated versus uneducated family background?

b. Does social stratification contribute to differential performance of different social groups of students? 
c. To what extent can an individual (coming from rural area, economically poor, and uneducated family background) show better performance in English overcoming such social stratification issues?

\section{SOCIAL STRATIFICATION IN JHARKHAND}

Social stratification has a great significance in modern sociology as it helps us to understand the society and its people. It is found in all society and tends to be transmitted from generations to generations. It refers to the categorization of individuals and groups in any society.

\section{SECONDARY LEVEL EDUCATION SYSTEM IN JHARKHAND}

With the establishment of the Jharkhand Academic Council, the Bihar Intermediate Education Council Act, 1992, the Bihar School Examination Board Act, 1952 (adapted as Jharkhand Secondary Examination Board Act, 2000) Bihar Sanskrit Education Board Act, 1981 And Bihar Board of Madrasa Educaiton Board Acts, 1981 were repealed. [13]Under the dynamic leadership of the State Govt. all the branches of education Secondary, Intermediate Sanskrit (Madhyama) and Madrasa wer brought under the single umbrella of Jharkhand Academic Council with the sole intention that all the branches of learning got equitable and unified attention so that they may grow into mighty oaks and no branch gets etiolated and languished in cold shade of neglect

\section{VARIATIONS IN ACADEMIC PERFORMANCE OF SECONDARY LEVEL STUDENTS}

Jharkhand had demonstrated remarkable progress in education after its existence .Every year the passing rate in the SSC exam breaks the record of the previous year. But there is a questionable gulf between the success rates of the urban and rural educational institutions, rich and poor students (economically solvent and poor group), educated and uneducated parental students. It is well known that schools in urban areas particularly those in the metropolitan cities dominate the passing rate (Daily Hindustan , 2012) On the contrary, most of the students who become unsuccessful in their academic examination are from rural areas and educational institutions with zero success are situated in rural setting where there are fewer facilities of education.

Therefore, we can say that academic success is related to students' living area and financial condition of students. Usually economically solvent students show better performance than those of economically poor across the town and village (With a few exceptions).This point is related to educational investment in Jharkhand. The larger proportion of secondary students in rural Jharkhand is either poor or disadvantaged, their families can not afford to make on optimum investment in heireducation . Such socio-economic realities influence the goal, expectation, future aim etc (Pratham (2007).. of the students and because of such factors students cannot equally concentrate on their study.

Here some socio-political realities may be considered. In Jharkhand, maximum educational institutions cannot provide quality education, [13]because of some social and political reasons. Considering this reality solvent parents invest money to send their children to private teachers or coaching centers as a supplement of institutional learning.

This is one of the main gaps that the poor students cannot fill up .As a result, students coming from poor family lag behind.. On that point educationists said that students of urban areas of solvent families made good the loss in lessons while the students of rural and poor families could not. Therefore, it is seen that private investment as an additional support to the students is a contributing factor in making variation in academic performance. Besides, economically solvent parents tend to send their children o better school, provide sufficient study materials, arrange better living and learning environment etc. Such necessary supports give them a chance to show better performance in academic examination than their counter part (poor students).

Like family income, level of fathers' and mothers' education also produces significant mean differences in the test and the SSC examination, which favors those students whose parents' have at least secondary education. Normally middle and upper class parents instill an academic background into their children before they even start their academic education which leads them ahead in academic field. (Akinwanmide, T. K. (2012).) hypothesizes that in most countries, parental education is positively related with graduation in a top institution and a prestigious field of study. Therefore, we can say that parental educations as well as students' family backgrounds significantly influence the future education and success of students.

In this connection some important comments by different philosophers and scholars on the importance of family in the education of child may be mentioned-

1. Education begins at birth and the proper nurse is the mother. - Rousseau

2. Home- a centre of love and affection is the best place and the first school of children.

-Pestalozzi

3. Mothers are the ideal teachers and informal education given by home is most effective and natural. - Froebel 
4. Child learns the first lesson of citizenship between the kiss of mother and the care of father. -Mazini

Above mentioned views clearly assert the importance of family, parental education and home environment for education and academic success of students. The foundation of education which children obtain from their family gradually influences the future academic performance as well as their success in all fields. According to Sharma, Yogendra K. (2009) each family has its own culture and set up quite distinct from the other, therefore no two children are the same at the beginning nor during development or as a grown up adult citizen. Therefore, we see that parental education, social background, family setting etc. highly influence students' habit, education, success etc.

\section{RESEARCH METHODOLOGY}

This study aims to investigate the unequal performance of different groups of students- having different social identity. This section focuses on the methods and procedures that had been applied to investigate about the topic of this study.

This study is mainly based on students' self reported information of their experience, education, facility, family background that can be related to their academic performance. For the investigation, the researcher has collected both qualitative and quantitative data from the learners who have completed their secondary level of education. This study has been conducted following mixed method.

The materials used for this study are questionnaires for students and teachers. The students are selected from a public college situated in urban area and from a private college in rural setting. From both the colleges, students have been selected randomly. All the student participants in that study had completed their secondary level education in the academic years 2011 and 2012 and 2013 they come from different areas, schools and family backgrounds. Accordingly, the researcher has collected some opinion, suggestions from several practicing English teachers of different educational institutions situated in urban and rural settings to know their perception about the unequal performance of different groups of students and to find out possible solutions for such problems.

In the students' questionnaires there are three types of questions- factual, behavioral, and attitudinal; and teachers' questionnaire included two types- factual and attitudinal.

a. Factual questions, which have been used to find out demographic characteristics (for example, age, residential location, socio-economic status, etc.) of the participants.

b. Behavioral questions are used to find out their life-style, habit, and personal history etc.

c. Attitudinal questions, which have been used to find out the perceptions, ideas and beliefs of the participants' about the research topic.

In students' questionnaire there are four sections. In Section $\mathbf{- A}$, questions are asked for knowing family information, status and background. In Section - B, questions have been asked to know about the learners' attitude of future plan, aim and view about English. The questions in Section $-\mathbf{C}$ are about the information of learners' academic background, facilities they have got and barriers they have encountered. And finally in Section -D, pedagogical questions(Asmari-A, A. R. (2010). are asked to know how they have learnt English. In teachers' questionnaire some questions are for practicing English teachers where some hypothesizes are given to rate them according to their importance in learning ESL/ EFL. In this questionnaire there are three sections (Section-A, Section-B and Section- C).

\section{LIMITATIONS OF THE STUDY}

In this study a small sample size (180 students and 51 English teachers) have participated. The study would be more representatives if a larger sample size was included to this. The study has got 39 student in group (L) [low/poor GPA obtaining group] and 71 students in group (B) [better/higher GPA obtaining group]. If the number of students in group (L) was equal to group (B), then the comparison would be more reliable.

There were not sufficient samples in some cases to make reliable comparative comment; for example, there were a few numbers of samples of highly educated mothers for the researcher to make a dependable comparison as to how mothers' education can be a factor in terms of students' academic performance.

The researcher has not explained the reasons of unequal performance of the same group students; for example, there is no explanation why the students, living in the same scholarly family culture have shown dissimilar performance. 


\section{DISCUSSION}

This chapter supplements a discussion about the reasons for low or better performance of students. Though the information collection was huge, the researcher has limited his discussion onto certain key points. Firstly he has focused on students' information, their judgment and thought on their causes of performance in English. Secondly, he has scrutinized the perception and suggestions of English teachers and subsequently identified some possible reasons(Crandall, J. (Ed.). (1998) of low or better performances.

This study stared with some set assumptions but many things had gone changed with the advancement of the study. However, the present study reveals that the participants - Secondary students and English teachers have rightly identified and confirmed that social inequality and social stratification factors directly or indirectly affects the academic performance of students. At surface level normally it is seen that only students' merit is the precondition of better performance but in real life experience the researcher has found that various social issues worked as catalyst or barrier to better performance.

In students' data, he has got almost details information of their academic performance, schooling, family background, educational qualification of family members, family profession, students' learning habit etc. social and psychological factors that seem to be affective to their English performance.

\section{A. STUDENTS' AREA OF RESIDENCE}

The information of students' living area stated in (L/B), says that better performance is related to students' living area. Success rates of students living at Thana area and urban area are $76.92 \%$ and $82.05 \%$. On the other hand, performance rates of students living at rural area are 48.04\%. Such information clearly indicates that rural students cannot perform better because of some social and geographical realities. In this respect the researcher points out some socio-cultural and socio-economic limitations of rural and poor students : In rural and under developed areas they have little chances to practice the target language and they get hardly any support from their family members and peer groups. In L2 acquisition research it is found that linguistic environment makes a difference in learning and performance. The role (If any) of environmental factor in first or second language acquisition affects the power and scope of any innate linguistic or cognitive contribution which becomes necessary to posit in the learner (Larsen-Freeman and Long, 1991). On this point we can hardly match the dissimilar linguistic environment of rural and urban areas. Urban students get the advantage of better linguistic environment than rural students.

\section{B. Educational Institution}

There is no denying of the contribution of school in better performance of students. Comparative shows that the success rates of students reading at urban educational institutions are $82.05 \%$. On the other hand, those of rural educational institutions are $52.38 \%$. saying that secondary schools in the urban areas are more efficient than those in the rural areas. Educational institution wise success rate actually depends on various facilitative of educational institutions. It is seen that normally in urban institutions meritorious students got admitted through competitive admission tests. (Md. Abdur Rashid ISSN 1930-2940)Therefore the chances of success of such talented students are more than rural students. It is perceived from the better performance rate from urban educational institutions that there the students get a competitive peer groups, better facilities and care. We know that a qualified teacher is the first condition of quality teaching. But unfortunately maximum English teachers of our country are less qualified (Adeyemi, D. A., \&Kalane, M. S. (2011). Majority of Jharkhand English teachers are not properly trained in teaching language. That means here is an acute shortage of qualified English teachers. This scarcity is more severe at the rural educational institutions where teachers' salary is so poor. Generally it is found that the quality of teaching, school management, school environment, and peer groups etc. directly or indirectly influence the performance of students

\section{Parental Education}

Parental education, scholarly family culture and educational success are closely linked. We know that a child receive his first lesson of speech in the family. During the first five years of life, the child lives freely under the care of parents and other family members. Children growing up with many books get three years more schooling than children from bookless home, independent of their parents' education, occupation and class ( Evans, et al., 2010). This opinion clearly reveals the importance and value of parental education and scholarly family culture in the education and performance of children.

In this respect, the researcher matches his finding from students' father and mothers' level of education from the comparativeand comments that the highest success rates $74.08 \%$ and $89.67 \%$ are perceived among such students whose father and mother are highly educated. However, the findings about the success rate of illiterate fathers' sons/daughters are not matching with our hypothesis. In this regard he has given different explanation about their better performance rate, commenting that perhaps they are self-motivated and succeeded because of their personal effort. 


\section{Parental Profession}

Behaviorist view of language acquisition simply claims that language development is the result of continuous practicing of a set of habit. According to this theory both L1(First Language ) and L2(Second Language) acquisition receive linguistic input from speakers in their environment. On this point the researcher relates his finding better performance rate of 1 st class category profession is in the highest position. Such better performance has nothing but one explanation that is they have got the support and inspiration from their parental profession and positive home environment. Evans, et al. (2010) asserts that this is as great an advantage as having university educated rather than unschooled parents, and twice the advantage of having a professional rather than unskilled father. As language learning is somehow related to habit formation so if parents are highly educated and professional then of course children will get the direct or indirect benefit of it. From the behavioristic point of view we can say that the personality, learning habit, future aim etc. of a child usually develop following his parents. (Md. Abdur Rashid ISSN 1930-2940) Students are normally positively motivated about learning English if they find their professional parents using it at home and professional life. Besides that, 1st class professional parents who are economically solvent can send their son/daughter to best schools in district, and towns what clearly make a difference from the son/daughter of low status parents.

\section{E. Family Income}

Family income is directly related to educational investment. When a family has financial stability, normally they invest more money on educational expenditure. In this respect, the survey finds that different level of family income makes differences in 10th grade students mean results in language proficiency test and SSC examination showed that students whose family income have higher income levels obtained they has shown higher score rate, $82.14 \%$ and $76.19 \%$ in their academic English performance.

\section{F. Helping Hand in Better Performance}

Although English classes are conducted regularly by school teachers, we know that some students take help from family members, private teachers, coaching centers and other sources. In this study we find that students who have taken help from their family members, their success rate is better. Accordingly, the students who solely follows institutional classes of their subject teacher at school their success rates are higher. On the contrary, students taking help from private tutors, coaching centers and from other sources have performed poorly. Here we note the importance of family as a powerful informal agent of education as (Sharma (2009) )asserts. Among different options like private tutor, coaching center etc. for outside support, in terms of education, there seem to be no alternative to educated family and parents.

\section{G. Attitude to English}

This topic is related to motivation. We know that in L2(Second Language) learning motivation is the crucial force which determines whether a learner embarks on a task at all, how much energy he or she devotes to it. If a learner attitude is negative, there may be strong internal barriers against learning. ( Larsen- Freeman and Long 1991), claimed a linear relationship between constellation of attitudes and second language learning success. Therefore, learners, attitude were said to have an important contribution to learning and performing in second language. In this study finds that students who have thought that English is highly important for them, their success rates are high, $64.41 \%$.

\section{H. Participants' Learning Needs}

Students' learning needs or purposes can affect their L2 learning rate; as such factors are also related to motivation that introduced two types of motivations: Integrative and Instrumental motivation.

a. Integrative motivation: Wanting to learn a language in order to communicate with people of another culture who speak it.

b. Instrumental motivation: wanting to learn a language because it will be useful for certain 'instrumental' goals such as getting a job, reading a foreign newspaper, passing an examination

Different researchers have reached at different conclusions about the affecting intensity of different types of motivation but the only reliable finding is that the intensity of motivation is more important than the type. This claim is supported by the finding of this study also .In this study it is found that whatever the motivation is, the performance of students are accelerated. the highest success rate, $78.26 \%$ is identified for the students whose learning purposes are 'personal and social'.

\section{Reasons of Showing Poor or Better Performance}

Identifying the exact reason for poor or better performance is really difficult. Sometimes learners actually don't know the reasons. In this study the researcher (Rustagi, P. (2008).)has seen that students of group (L) (who have showed low performance) identified "not getting extra tuition" as the 1st reason; "home and 
surrounding environment' and 'self-weaknesses as the second and third reasons. On the contrary, the students of group (B) (who have showed better performance) have not mentioned 'getting extra tutor assistance' as the first contributing factor for their better performance. They rather find that their 'home and surrounding environment' and 'self-effort' are the main contributing factors in their better performance. Now the question arises whether extra-tuition can help the students in their better performance. (Md. Abdur Rashid ISSN 1930-2940) Here the researcher gives the answer saying that yes, it helps students, but extra-tuition is never the alternative to selfeffort, motivation, scholarly family environment and positive surrounding for learning language.

\section{J. Extra Tutor Assistance}

As maximum schools are not providing proper education to the students, solvent parents are investing additional money for private education/extra-tuition, as it is instanced by a report in a national English daily, expressing concern over the result of SSC examination-2011, educationists said capitalism had engulfed the country's education system. Students backed by solvent families are achieving glorious result while students from poor families are failing to obtain even pass marks as schools fail to provide quality education to them (The Times of India , 2011). In Jharkhand it is the general picture that solvent families are taking the help of coaching centers whereas poor families are failing to provide necessary English books, materials and most importantly private lessons in English(Adeyemi, D. A., \&Kalane, M. S. (2011).). Such additional supports to the solvent students clearly make difference in academic performance. In this study similar picture is also found that extra tutor assistance helps the students in better performance. And about the existence of distinguished data of students group who have not taken any extra tutor assistance but performed better, the argument is like the previous point that perhaps they are self-esteemed or have got help from their family members.

\section{K. Participants' Access to Modern Amenities}

Through this point, the researcher has tried to examine his hypothesis that students who use modern amenities (mobile phone, internet, satellite TV etc.) have more chances to perform better in English. But unfortunately he has not got sufficient data to support his claim; more research is needed in this point.

\section{Conclusion and Future Recommendation Conclusion}

Summarizing the data provided by the participating students and English teachers, it is found that there are several factors responsible for unequal performance of different groups of students. Here the factors identified are: dissimilar living environment and standard, unequal facilities of different categories of educational institutions, parental education and family culture, additional investment for extra tutor assistance, self-motivation and personal effort etc. This study has been initiated with a view to investigating some sociolinguistic variables that seem to affect the academic performance in English at secondary level education in Jharkhand. In this study, the first and second research questions are related to student's social identity, living standard, family lineage and family culture proved very much influential to the English performance. The researcher has found that students coming from urban area, urban school, solvent family, and scholarly family culture performed better than the other group. However, the better performance rates of such students are in few cases very marginal. With regard to the 3rd research question, the researcher has found that in some extents when the learner is highly motivated and serious, he can overcome any kind of social, economic and unfavorable social and family barriers.

Social stratification and social inequality are present in every society, culture and country. It can hardly be sidestepped, although many people tend to turn a blind eye towards such issues. In the curriculum development, Jharkhand policy makers never think about such social and psychological barriers of poor and disadvantaged students. The study makes it clear that students' English performance varies according to their social identity. Therefore, some measures and steps should be taken by policy makers, teachers and parents to reduce the unequal performance of different groups of students.

\section{Future Recommendation}

There are several affecting factors for uneven performance of different groups of students that were identified related to students' living area, educational institution, parental education and profession, family income and culture etc. Though the researcher has got plenty of suggestions from experienced English teachers, considering socio-cultural and socio-economic realities of Jharkhand, here he is recommending only a few of them:

The facility of education must be decentralized. Logistic support should be provided to the rural educational institutions. In addition, rural educational institutions should be brought under strong monitoring and well-educated members should be included in the committees to ensure a better educational environment.

A qualified teacher supplies life-blood to teaching and language teaching is no exception. Hence, more qualified and motivated English teachers should be appointed where there is a shortage. Accordingly, regular professional 
development of the teachers is also essential. Regular in-service training for language teachers need to be arranged both from the Government and by the institutions themselves.

Classroom teaching should be made more effective so the poor students can fill the gap of the family support for education. Again, we know that the poor guardians of rural areas cannot afford to provide necessary teaching materials for their son/daughter. So, students from poor family backgrounds may be provided with special scholarships of financial help from the Government.

The authority can refurnish and replenish the existing library with modern technology and equipment facility so that language learning can be made easier for all kinds of students. If possible extracurricular activities relating knowledge of English (e.g. English debate, open discussion session etc.) can also be arranged.

\section{REFERENCES:}

[1] Vygotsky, L. S. (1978). Mind and society: The development of higher psychological process. Cambridge:Harvard University Press. http://esl.fis.edu

[2] Sharmna, Yogendra K. (2009). Foundation of Sociology of Educatio,. Kanishka publishers, New Delhi-110003.

[3] Larsen-Freeman, Diane (2001). Techniques and Principles in Language Teaching, Oxford University Press.

[4] Ofodu, G. O., \&Lawal, R. A. (2011, November). Gender parity and secondary school students' achievement in English comprehension.Proceedings of the London International Conference on Education (2011), 96-101. London, United Kingdom.

[5] Adeyemi, D. A., \&Kalane, M. S. (2011). English in Botswana junior secondary curriculum.International Journal of Educational Sciences. Delhi: India.

[6] Akinwanmide, T. K. (2012). The influence of process approach on English as Second Language students performances in essay writing. English Language Teaching, 5(3), 16-29. http://doi.org/10.5539/elt.v5n3p16

[7] Larsen-Freeman, Diane and Long, Michael (1991). An Introduction to Second Language Acquisition Research, Longman Group UK Limited.

[8] Larsen-Freeman, Diane (2001). Techniques and Principles in Language Teaching, Oxford University Press.

[9] Primary Education in Jharkhand Author(s): Kumar Rana and Samantak Das Source: Economic and Political Weekly, Vol. 39, No. 11 (Mar. 13-19, 2004), pp. 1171+1173-1178 Published by: Economic and Political Weekly Stable URL: http://www.jstor.org/stable/4414769

[10] Rustagi, P. (2008). 'Towards UEE in Jharkhand Issues of Equality, Quality andInclusion', Institute for Human Development, presented at 'National Seminaron Growth and Human Development in Jharkhand Perspectives and Policies'4-5 July 2008 Ranchi India

[11] Pratham (2007). Annual Status of Education Report. (Retrieved on $14 \quad$ August 2008from http://www.pratham.org/aserrep.php)

[12] GOI (Government of India). 2007. Report of the National Knowledge Commission. New Delhi: GOI. Available online at www.knowledgecommission.gov.in

[13] Official Website of Government of Jharkhand.htm

[14] Kurrien, J. 2005. Notes for the Meeting of the National Focus Group onTeaching of English and Notes on Introduction of English at the Primary Stage. Unpublished document.

[15] Md. Abdur Rashid, A Sociolinguistic Study of Social Stratification in Bangladesh and Its Impact on Academic Performance in English at Secondary Level Education ISSN 1930-2940

[16] Pandey, G. 2011. An 'English goddess' for India's down-trodden. BBC News South Asia 15 February 2011. Available online at www.bbc.co.uk/news/world-south-asia-12355740.

[17] Rao, S. 2008. India's language debates and education of linguistic minorities. Economic and Political Weekly 6 September 2008 .

Walia, J.S.,Dr., Philosophical and Sociological Basis of Education, Ahim Paul Publishers, Jalandhar City, (2008), p. 73 Educational Curriculum, 2012-13, Jharkhand Board, Ranchi.

Srivastva, Archana. (2009). English for Specific Purposes: Its meaning and purposes in present Indian scenario. ESP World, Volume 8, Issue 1 (22). Retrieved October 10, 2010 from www.esp-world.info/contents.htm

[18] Tsui, A. (2003). Understanding expertise in teaching: Case studies of second language teachers. Cambridge: Cambridge University Press.

[19] Gokak, V.K. (1964). English in India: Its present and future. London: Asia Publishing House.

[20] Crandall, J. (Ed.). (1998). Collaborate and cooperate: Teacher education for integrating language and content instruction. English Teaching Forum, 36. 2-9

[21] Asmari-A, A. R. (2010). The Effectiveness of Technology Use in Pre-service EFL Teacher

[22] Education. The Journal of English Language Teaching (India), Vol. 48/4, 3-10.

[23] National Institute of Education Awareness and Planning. "District System Information on

[24] Education, 2008." www.dise.in/ar2005.html

[25] [26] Evans, M.D.R., et.al. (2010).Family scholarly culture and educational success. Books and schooling in 27 nations, Research in Social Stratification and Mobility.doi:10.1016/J .rssm.2010.01.002.

Annex-2

Students' questionnaire

[Students will fill in/give ? $\sqrt{ }$ mark this form with the help of researcher]

\section{Section A}

1. Name:

2. Permanent Address: Post office /Village:

Thana:

District/City:

3. Where do you live now? : a. Own house b. rented house
It? fslocation :
a. City corporation area $\quad$ b. Thana
c. Union

4. If rented, then its monthly rent:

Rs. 
5. Whom do you live with? : A. Your family b. Relative. c. Others

6. Father's information

\begin{tabular}{|l|l|l|l|l|}
\hline $\begin{array}{l}\text { Age } \\
\text { (approximate } \\
\text { year) }\end{array}$ & $\begin{array}{l}\text { Educational } \\
\text { qualification } \\
\text { (maximum degree } \\
\text { he obtained) }\end{array}$ & $\begin{array}{l}\text { Profession } \\
\text { (details) }\end{array}$ & $\begin{array}{l}\text { Monthly income } \\
\text { (approximate) Rs.. }\end{array}$ & $\begin{array}{l}\text { Total working } \\
\text { hour(daily }\end{array}$ \\
\hline & & & & \\
\hline
\end{tabular}

\section{Mother's information}

\begin{tabular}{|l|l|l|l|l|}
\hline $\begin{array}{l}\text { Age } \begin{array}{l}\text { Approximate } \\
\text { year) }\end{array} \\
\text { yeducational }\end{array}$ & $\begin{array}{l}\text { Profession } \\
\text { qualification } \\
\text { (maximum degree } \\
\text { he obtained) }\end{array}$ & $\begin{array}{l}\text { Monthly income } \\
\text { (approximate) Rs.. }\end{array}$ & $\begin{array}{l}\text { Total working } \\
\text { hour(daily }\end{array}$ \\
\hline & & House wife & 00 & 00 \\
\cline { 2 - 5 } & & & \\
\hline
\end{tabular}

08. Which language did you mostly use in your family environment?

a. English b. Hindi c. English \&Hindi d. Local dialect

09. Who helped you more in learning English?

a. Family Members b. School teacher c. Private teacher d. Friends.

10. Which one is given first priority in your family?

a. Educational expenditure

b. Food expenditure

c. Social and family functional expenditure

d. Saving money

e. Investing money in land buying

11. Which culture influences you most?

\section{Section B}

a. Traditional Hindi culture b. Progressive Hindi culture

c. Hybrid Hindi culture d. Hindi culture e. American culture f. British culture

12. What is the maximum academic degree you want to obtain?

a. PhD b. Master's degree c. Bachelor's degree d. H.S.C

13. How important, do you think, is English in your practical life?

a. Highly b. Fairly c. A little d.Not at all.

14. Why do you need English?

a. To get a better GPA

b. For my prestige in friend circle .

c. To read English books and newspapers, watch English movies, program etc.

d. To get better job.

e. For higher study in foreign country

\section{Section C}

15. Name of secondary school

16. Its address : Thana:

District/City

17. SSC passing year : a. 2013 b. 2012 c.2011

18. Obtained CGPA in SSC

19. GPA in English :

20. What were the

approximate numbers of students in your

class?

a. 50 b. 75 c. $100 \mathrm{~d}$. above 150

21. Which language did you mostly use in English class room?

a. English b. Hindi c. English \& Hindi d. Local dialect

22. Which language did your teachers mostly use at School?

a. English b. Hindi c. English \&Hindii d. Local dialect 
23.A. What is your reason of getting poor GPA in English?

a. Not getting support and help from my family members

b. My weakness in English.

c. Not getting enough help from subject teachers.

d. My home and surrounding environment.

e. I did not get extra tuition in English.

23 .B. What is the secret of your higher GPA in English than your CGPA?

a. Getting support and help from your family member.

b. Personal effort.

c. The help of my subject teacher.

d. My circle and family environment.

e. I got extra tuition in English.

\section{Section D}

24. How often did you use English outside of your school? a. $75 \%$ b. $50 \%$ c. $25 \%$ d. $10 \%$ e. $5 \%$ f. $0 \%$

\section{Did you go to any private teacher/coaching center for reading English?}

a. Yes

b. No

26. How long did you study English under private /extra tuition?

a. 6 months b. 1 year c. 2 years d. 3 years e. 4 years

27. What do you do usually at your leisure period? (After school)

a. Play in the field b. Watch TV c. Read hindi books, papers etc.

d. Read English books, papers etc. e. Spend time with friends $\mathbf{f}$. Spend time with family

28. What kind of TV/radio channel/program you like most?

a. Local b. Hindi c. English d. All

29. Which modern amenities do have access?

a. Mobile phone (call, sms, mms)

b. Internet in mobile phone

c. Internet

e. Satellite TV

f. Above all

30. Why do you have access in such modern amenities?

a. For learning English

b. For face book, Email check etc.

c. For news

d. For You tube movie

e. For any kind of information

Teachers' questionnaire

Annex-3

\section{[English teachers will fill in this form with the help of researcher]}

Section -A

1. Name :

2. Name of Institution (working institution):

3. Where is it situated? : a. City corporation area b. Thana c. Union

4. Educational qualification :

5. Experience : year

(Approximate)

Section-B

6 . Give a rating point $(1,2,3)$ in the right of the following hypothesis (The most reasonable one will get rate 1 , next one 2 etc.)

\begin{tabular}{|l|l|l|}
\hline No. & & point \\
\hline a. & $\begin{array}{l}\text { Urban students have more chances to show better performance in academic English at } \\
\text { secondary level than the rural students. }\end{array}$ & \\
\hline b. & One's social position can affect one's academic performance in English. & \\
\hline c. & One's family condition (economic) can affect one's academic performance in English & \\
\hline d. & Students coming from educated family have more chances to show better performance in & \\
\hline
\end{tabular}


A Sociolinguistic Study of Social Stratification in Jharkhand and...

\begin{tabular}{|l|l|l|}
\hline & Academic English & \\
\hline e. & Student's living environment can affect his Second language (English) learning. & \\
\hline f. & Local and family culture can affect one's academic performance in English. & \\
\hline
\end{tabular}

7. Give a rating point $(1,2,3)$ in the right of the following suggestions: (The most reasonable one will get rate 1 , next one 2 etc.)

\begin{tabular}{|l|l|l|}
\hline No. & & point \\
\hline a. & For better performance in English qualified subject teachers are needed. & \\
\hline b. & For better performance in English favorable school environment is essential. & \\
\hline c. & For better performance in English extra tutor assistance in English is needed. & \\
\hline d. & For better performance in English better family environment is needed. & \\
\hline e. & For better performance in English personal effort is needed & \\
\hline f. & . For better performance in English student's lifestyle should be improved & \\
\hline
\end{tabular}

Section-C

8. What are your suggestions in reducing such difference in the different learners?

\begin{tabular}{|l|l|}
\hline a. & \\
\hline b. & \\
\hline c. & \\
\hline d. & \\
\hline e. & \\
\hline
\end{tabular}

